\title{
8
}
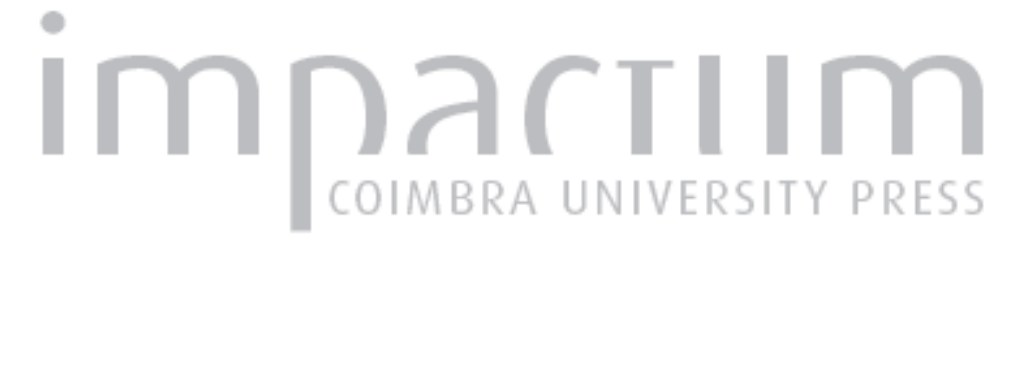

\section{A memória e o outro da História: topografias da memória entre Franz Kafka e Walter Benjamin}

\author{
Autor(es): $\quad$ Cuozzo, Gianluca
}

Publicado por: Imprensa da Universidade de Coimbra

URL persistente:

URl:http://hdl.handle.net/10316.2/35502

DOI:

DOI:http://dx.doi.org/10.14195/0870-4112_11_6

Accessed : $\quad$ 26-Apr-2023 08:47:06

A navegação consulta e descarregamento dos títulos inseridos nas Bibliotecas Digitais UC Digitalis, UC Pombalina e UC Impactum, pressupõem a aceitação plena e sem reservas dos Termos e Condições de Uso destas Bibliotecas Digitais, disponíveis em https://digitalis.uc.pt/pt-pt/termos.

Conforme exposto nos referidos Termos e Condições de Uso, o descarregamento de títulos de acesso restrito requer uma licença válida de autorização devendo o utilizador aceder ao(s) documento(s) a partir de um endereço de IP da instituição detentora da supramencionada licença.

Ao utilizador é apenas permitido o descarregamento para uso pessoal, pelo que o emprego do(s) título(s) descarregado(s) para outro fim, designadamente comercial, carece de autorização do respetivo autor ou editor da obra.

Na medida em que todas as obras da UC Digitalis se encontram protegidas pelo Código do Direito de Autor e Direitos Conexos e demais legislação aplicável, toda a cópia, parcial ou total, deste documento, nos casos em que é legalmente admitida, deverá conter ou fazer-se acompanhar por este aviso.

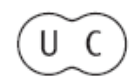




\section{ESTÉTICA E POLÍTICA}

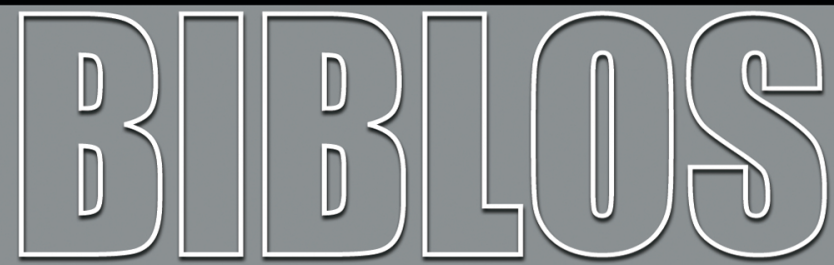

REVISTA DA FACULDADE DE LETRAS UNIVERSIDADE DE COIMBRA 
Biblos, n. s. XI (2013) 185-213

DOI: http://dx.doi.org/10.14195/0870-4112_11_6

Gianluca Cuozzo

Dipartimento di Filosofia e Scienza dell'Educazione - Universitá Degli Studi di Torino

\title{
A MEMÓRIA E O OUTRO DA HISTÓRIA TOPOGRAFIAS DA MEMÓRIA ENTRE FRANZ KAFKA E WALTER BENJAMIN
}

\section{Resumo}

O homem ocidental está a atravessar uma fase de prolongada e programática latência. O valor da memória, por mais renegado que seja pela hodierna sociedade do usa e deita-fora, continua no entanto a ser o centro da formação de um pensamento crítico que saiba enfrentar os desafios do nosso presente: a crise económica/financeira/ecológica que se instala no coração do bem-estar material, que lança uma sombra profunda sobre as nossas escolhas irresponsáveis - escolhas que, em definitivo, são fiéis à trindade blasfema 'globalização-ocidentalização-desenvolvimento', a estrutura suicida da nova idade do ferro planetária. Seguir os percursos tortuosos do nosso recordar impõe uma reflexão sobre aquela que pode ser definida como uma arquitectónica da memória: Agostinho, Piranesi, Kafka, Magritte e Auster são alguns dos guias escolhidos nesta aventura, enquanto Benjamin é o farol filosófico e político desta cada vez mais necessária 'arqueologia do saber'.

Palavras-chave: Memória, esquecimento, teoria crítica, despertar.

\begin{abstract}
The Western civilization is going through a long programmatic latency phase. The value of memory, though neglected in the current throw-away society, remains crucial to the development of a critical thinking capable of facing the multiple challenges posed by the present: above all the economic/ financial/ecological crisis - which lies at the heart of material wealth - and which casts a grim shadow over our irresponsible choices - i.e. those choices that are the faithful emanation of the blaspheme trinity "globalization-westernization-development", the suicidal structure of the new planetary Iron-age. Such a (tortuous) trip down memory lane imposes a meditation on what could be defined an "architectonics of memory". St. Augustine, Piranesi, Kafka, Magritte, and Auster are only a few of the guides leading us in this adventure, while Benjamin is the philosophical and political beacon of light in this imperative "archaeology of knowledge".
\end{abstract}

Keywords: Memory, Oblivion, Critical Theory, Reawakening. 
A memória, entre as outras potências da alma, tem isto de particular: ela não parece uma faculdade disponível ao homem. A memória, poderia dizer-se, é a sede do inapropriável, de alguma coisa que escapa ao controle humano; e não apenas devido ao problema, descrito magistralmente por Proust, da memória involuntária, segundo o qual o souvenir estaria desligado de qualquer intenção consciente - de tal modo que as recordações mais verdadeiras seriam "visões tanto mais autênticas e reveladoras quanto menos sujeitas ao controle da inteligência analítica"1.

Agostinho, nas Confissões, deu uma das definições dela ao mesmo tempo mais profundas e terríveis: "Grande é esta potência da memória, imensamente grande, Deus meu, um santuário vasto, infinito. Quem chegará alguma vez ao seu fundo? E todavia é uma faculdade do meu espírito, ligada à minha natureza. Na realidade não consigo compreender tudo aquilo que sou. Seria, pois, o espírito demasiado estreito para se compreender a si mesmo? E onde estaria o quanto de si não compreende? Fora de si mais que em si mesmo?" 2 .

O problema, expresso em termos quantitativos, é pois o do continente e do conteúdo, onde o conteúdo - contra toda a lógica ordinária - supera em muito o continente: como a "circunferência do oceano" abraça toda a terra; como "uma vida vária, multiforme, de uma "imensidade poderosa' "é superior ao nosso dizer eu, de cada vez circunstanciado e pontual ${ }^{3}$. Se a memória é semelhante a um grande templo, um santuário ou um palácio, quando recordo é como se me aventurasse nos meandros deste antigo edifício, imenso e labiríntico, em que consiste o substrato profundo do espírito criado enquanto ad Dei imaginem. A memória, então, é posta em segurança dentro de mim; mas ela, por sua vez, compreende-me como um território mais vasto e misterioso, por que anseio como se fosse uma "alegria antiga: uma topografia de sentido em que o tempo é retomado espacialmente em constelação daqui, pois, o filão dos "lugares da memória" típicos da Mnemotécnica, de Raimundo Lullo e Giordano Bruno.

${ }^{1}$ A. GrILli, Polarità e antinomie in Á la recherche du temps perdu, in Journées Proust III, La Recherche tra apocalisse e salvezza, atti del convegno di Urbino, 14 e 15 maggio 2003, a cura di D. D’Agostini, Fasano, Schena Editore, 2005, p. 173.

${ }^{2}$ Sant' Agostino, Confessiones X, 15.

${ }^{3}$ Ivi X, 17. 
Apercebo-me de ser parte de mim mesmo no momento em que, penetrando nas estâncias secretas das recordações, me dou conta, com desconcerto, do ecoar dos meus próprios passos, do ruído produzido pelas peregrinações de todo o meu ser (o Eu que recorda) numa parte depositada do próprio eu (a parte que contém o todo). A faculdade da memória, escreve ainda Agostinho, "é grandiosa. Inspira quase um sentido de terror, Deus meu, a sua infinita e profunda complexidade. E isto é o espírito, e isto sou eu próprio. O que sou pois, Deus meu? Qual é a minha natureza?" 4.

O homem, recordando, ajusta no fundo contas com a sua inata disproportio: 'o ser mais e menos que si próprio', pondo-se, em simultâneo, como o Mesmo que recorda e como o Outro de si (como lugar da lembrança que inclui em si um sujeito à mercê do seu 'mais que passado', do seu 'mais que si próprio'). Je est un autre, escrevia Rimbaud na sua Saison em enfer (de 1879); quando recordo descubro que as minhas raízes mergulham nas profundidades insondáveis de uma alma que é mais do que aquilo que sou - o outro, o meu duplo, a minha imagem invertida, diga-se o que se disser. O cais para a visão e o reconhecimento de si através da lembrança coincide assim com o naufrágio num vasto oceano, com a perda das certezas do eu - um enésimo "naufrágio com espectador' (diria Blumenberg ${ }^{5}$ ), mas onde sujeito e objecto deste 'espectáculo' sublime são um só e idêntico idem, um unicum em si próprio quebrado, lacerado e à mercê das ondas do infinito e do eterno que o envolvem.

Um célebre romancista dos Estados Unidos, Paul Auster, na tentativa de recordar a verdadeira imagem do pai, e, portanto, de se saber o seu filho (penso no romance autobiográfico $A$ invenção da solidão, de 1982), diz encontrar-se perante o mesmo enigma da memória correspondente ao de Agostinho. Procurar a própria vida nas recordações de um tempo, no caso de Auster, não põe o sujeito face a um estado de ignorância por defeito (segundo o qual nem tudo o que fui está ainda disponível na memória) mas antes - poderia dizer-se - per excessum de informações disponíveis no território desnorteante da memória: “A memória como lugar, edifício, com colunas, pórticos, cornijas. O corpo na mente,

\footnotetext{
${ }^{4}$ Ibid.

${ }^{5}$ H. Blumenberg, Schiffbruch mit Zuschauer, Frankfurt a. M., Suhrkamp,
} 1979. 
como que caminhando nela, transferindo-se de um lugar para outro, e o rumor dos nossos passos que se deslocam de um lugar para outro" 6 . Eu, quando creio ter apanhado vestígios que testemunham a minha presença na vida de um tempo, como testemunho da continuidade biográfica, vejo-me na realidade como sendo outro de mim; de tal modo que, quando se está a tal ponto fragmentado, procurando destilar a própria autobiografia - escreve Auster - não se pode escrever sobre si senão na terceira pessoa: eu próprio como um outro, ou melhor eu próprio como o outro - uma espécie de Doppelgänger que, preservando recordações inacessíveis ao eu, dispõe da minha vida como arqui-história do sujeito: um passado originário (Urgeschichte) que não pode ser reduzido às categorias da subjectividade nem da psicologia. Recordar, dadas estas premissas, torna-se em Auster verdadeiramente metáfora da perda:

Devendo definir numa imagem este processo [mnemónico: $N d A$ ] das nossas mentes, começa a delinear-se uma rede de caminhos semelhantes a um desenho do sistema circulatório humano (coração, artérias, veias, vasos capilares), ou a um mapa (por exemplo uma planta das ruas, de preferência relativo a uma grande cidade, ou uma carta de estradas que se alongam, se bifurcam e serpenteiam através de um continente); de tal modo que o que verdadeiramente fazemos ao passear por uma cidade é pensar, e pensar que os nossos pensamentos formam um itinerário, e este itinerário corresponde mais ou menos aos passos que tivermos dado $[\ldots]^{7}$.

O mesmo acontece ao andarmos à caça dos vestígios mnésicos do nosso passado: perdemo-nos aí em caminhos que não levam a lugar algum.

Quem poderá suportar, poder-se-ia perguntar, esta projecção anamórfica do mesmo sobre a superfície opaca e deformante das recordações? Os vestígios e as imagens do eu, penetrando para além das recordações conscientes, rebelam-se em relação ao sujeito, mostram a sua autonomia - como acontece com Balduin, o protagonista de Der Student von Prag, obra prima do expressionismo alemão, aparecida em 1913, com a direcção de Stellan Rye): a parábola muito faustiana de

6 P. Auster, The Invention of Solitude, Boston, Faber \& Faber, 1982 (trad. it. L'invenzione della solitudine, a cura di M. Bocchiola, Torino, Einaudi, 1997, p. 81).

${ }^{7}$ Ivi, p. 123. 
Balduin levá-lo-á, numa cena tópica do filme, ao ponto de entrar em duelo com a própria imagem, como se ela fosse um outro do mesmo que nele se reflecte.



Foto 1

No fundo o eu é o resultado de escolhas que, por mais ou menos conscientes que sejam, deixam nas suas costas um reiectus, outros eu descartados e recusados que jamais verão a luz; não há projecto (proiectus) que, por assim dizer, não produza como desvio de sentido um 'rejeitado', um legado indesejado e repelido para a não visibilidade, que acompanha cada projecto de sentido como um halo de possibilidades vencidas e superadas. Isto, de resto, acontece também na produção literária, como o ilustra magistralmente Italo Calvino no conto La pubelle agréée: enquanto escrevo, "eu expulso-me, cuspo-me, desprezo-me no mesmo movimento em que 'eu' pretendo pôr-me [...], eu estou-me tornando um outro à custa da minha própria morte. No trajecto em que devenho, faço o parto de mim próprio na violência do soluço, do vómito" ${ }^{8}$. O cesto de papéis no canto do escritório, no fim deste

${ }^{8}$ J. Kristeva, Pouvoir de l'Horreur. Essai sur l'abjection, Paris, Seuil, 1980 (trad. it. Poteri dell'orrore. Saggio sull'abiezione, a cura di A. Scalco, Milano, Spirali, 2006, p. 5). 
doloroso processo de selecção e de amputação - em que o eu narrador, no fim, se mostra como o sobrevivente, aquele que sobreviveu tout court entre outros eus que foram alienados - torna-se o lugar das histórias descartadas, dos contos não publicados, das palavras jamais ditas. $\mathrm{O}$ cesto das recusas, dito de outra forma, surge aqui como repositório das projecções imaginativas de um eu que, qual alter ego rejeitado pelo escritor, jamais se revelou como tal. Como se pode acreditar pois que naquele lugar do esquecido, o poço da memória, haja qualquer algo de mim que ainda me olha, pronto para ser despertado pela minha faculdade de recordar em vista de um reconhecimento, de um aumento de consciência do eu? De acordo com o princípio do garbage in-garbage out formulado por John Scanlan - segundo o qual o nosso eu se constrói através de um processo alquímico pelo qual qualquer coisa de bruto é assumido no nosso projecto de ordem para ser limpo de novo, purificado e ordenado; enquanto alguma coisa de outro, inevitavelmente, acaba aí por ser expulso como escória, recusa e nonsense completamente sem préstimo (“a nulidade do inútil”) ${ }^{9}$ - escreve Calvino,

O importante é que neste gesto quotidiano [do deitar fora: $N d A$ ] eu confirme a necessidade de me separar de uma parte daquilo que era meu, os despojos ou crisálida ou limão espremido do viver, para que disso reste a substância, para que amanhã eu possa identificar-me por completo (sem resíduos) no que sou e tenho. Só deitando fora posso assegurar-me de que qualquer coisa de mim não foi ainda deitado fora e talvez não seja nem será de deitar fora ${ }^{10}$.

No acto de recordar, pois, é como se alguém se reflectisse a si próprio num espelho enfeitiçado, vislumbrando-se à sua superfície como essencialmente outro daquilo que é. O espelho da memória, como instrumento de 'confirmação imagística' do eu, é como se evidenciasse um 'degrau' no interior do subjectum, uma eliminação da consciência que desperta desconcerto e perplexidade naquele que olha. Este desnível, que compromete o acto de reconstituição do sujeito na auto-refl-

${ }^{9}$ J. Scanlan, On Garbage, London, Reaktion Books, 2005 (trad. It. Spazzatura, a cura di M. Monterisi, Roma, Donzelli, 2006, p. 87).

${ }^{10}$ I. Calvino, La poubelle agréée, in IdEM, La strada di San Giovanni, Milano, Mondadori, 1990, p. 276. 
lexão rememorante, para Agostinho testemunha a presença do infinito (Deus) na alma humana; enquanto para Auster, de modo bem diferente, o sujeito revela-se nessa auto-reflexão como à mercê de uma história enigmática de que não pode dispor, deslocando a metáfora espacial do santuário da memória para a das metrópoles tentaculares, lugar de perda por excelência: "Começo a compreender a absurdidade da tarefa que me propus", escreve Auster no romance citado; enquanto experimento recordar

Tenho a impressão de me dirigir para uma meta, de saber o que queria dizer, mas quanto mais avanço mais cresce a certeza de que a estrada para chegar ao meu fim [a de traçar uma imagem nítida do pai através das recordações: $N d A$ ] não existe. Devo inventar o caminho a cada passo, e isto significa que jamais estou seguro do lugar onde me encontro. Tenho a impressão de me movimentar em círculo, de voltar permanentemente sobre os meus próprios passos, de me dispersar em várias direcções. E ainda que consiga dar algum passo em frente, não estou de facto convencido de que me levará onde penso ir. $\mathrm{O}$ facto de vaguear no deserto não significa que exista uma terra prometida ${ }^{11}$.

O espelhamento mnemónico, no seu alcance 'desindividuante', tem assim pelo menos, dois sentidos: por um lado, representa a repatriação tranquilizadora do sujeito no refúgio da sua origem (e é este o caso de Agostinho) - onde a memória é semelhante a um porto seguro, o qual põe fim a todo o Streben e Sehnsucht do divino; por outro lado, aponta para a perda de qualquer certeza por parte do eu, encontrando-se aqui quem recorda à mercê do desconhecido e das trevas "como se o sentido da própria continuidade o abandonasse" ${ }^{12}$. Ambos os paradigmas são tentativas de responder ao que se poderia chamar o paradoxo do conteúdo mnemónico, que como parte contém o todo do sujeito que recorda - lembrem-se as palavras de Agostinho, segundo o qual "o espírito seria demasiado estreito para se compreender a si próprio". Mas enquanto o primeiro paradigma é o que definirei como repatriação 'teomórfica' do sujeito (de matriz essencialmente teológica), o segundo - como escreve

\footnotetext{
${ }^{11}$ P. Auster, op. cit., p. 39.

12 Ivi, p. 29.
} 
o hebreu Auster - é o do Exxodo permanente do eu nas regiões inapreensíveis da memória, de que foi um magnífico evocador Th. Mann em As histórias de Jacob:

Profundo é o poço da memória. Ou deveríamos dizer antes imperscrutável? Imperscrutável também, e talvez agora mais do que nunca, quando se discute e se interroga o passado do homem e só dele: deste ser enigmático que encerra em si a nossa existência [...] e cujo mistério, como é compreensível, dá lume e tensão a qualquer palavra nossa, urgência a qualquer um dos nossos problemas. Porque [mesmo neste caso acontece que quanto mais se escava no subterrâneo mundo do passado, quanto mais profundamente se penetra e se procura, tanto mais os primórdios do humano, da sua história, da sua civilização se revelam completamente insondáveis e, mesmo fazendo descer para lonjuras temporais fabulosas sondas, continuamente mais e mais recuam para abismos sem fundo ${ }^{13}$.

Quero tomar como guia duas imagens artísticas para descrever esta alternativa conceptual - Leitbilder em senti próprio e verdadeiro que poderão servir de guias nos labirintos da memória: o célebre auot-retrato de Albrecht Dürer de 1500 (Sebstporträt i, Pelzmantel) e La reproduction interdite de René Magritte, tela surrealista acabada em 1937. Elas colocam-se idealmente nos dois extremos da experiência da memória até aqui delineada - a repatriação/reconhecimento no divino (experiência teomórfica) e a dispersão do sujeito numa história inenarrável (êxodo e errância sem fim nas recordações, na ausência de uma "terra prometida" do reconhecimento), dispersão que põe em crise a continuidade histórica do sujeito.

Na primeira imagem o pintor alemão, reflectindo-se no espelho do próprio auto-retrato, recorda-se da própria origem divina. Com efeito, como foi notado, trata-se do "único retrato de Dürer em que a figura é colocada de maneira rigidamente frontal e vertical" ${ }^{14}$ : o pintor, evi-

${ }^{13}$ Тн. MAnN, Joseph und seine Brüder, in Gesammelte Werke in dreizehn Bänden, Frankfurt a. M., Fischer, 1990, voll. IV-V (trad. it. Le storie di Giacobbe, in Idem, Giuseppe e i suoi fratelli, a cura di B. Arzeni, Milano, Mondadori, 2006, p. 5).

${ }^{14}$ E. Panofsky, The Life and the Art of Albrecht Dürer, Princeton, Princeton University Press, 1955 (trad. it. La vita e l'opera di Albrecht Dürer, a cura di C. 
dentemente, representou-se a si próprio com os traços tradicionais de um ícone de Cristo (vera ikon), e a representação poderia "quase valer como imagem da obra De visione Dei" de Nicolau de Cusa: onde "o Deus que olha o homem é imagem do homem que se olha a si mesmo como a Deus" " ${ }^{15}$. Cito do De visione Dei do Cusano. No seu tempo conhecido como Livro do ícone (ele deveria ser acompanhado de uma imagem de Cristo cuncta videns):

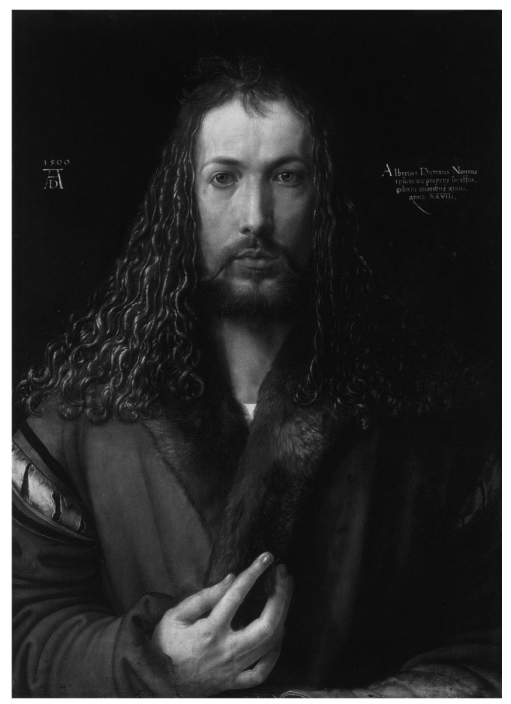

Foto 2

Assim compreendo que o teu rosto, Senhor, é anterior a todas as faces formáveis, é o modelo e a verdade de todas as faces e todas as faces são imagens da tua face insuscetível de contração ou participação. Daí que toda a face que pode olhar para a tua face nada veja que seja diferente ou diverso de si própria, porque vê a sua verdade ${ }^{16}$.

Basso, Milano, Abscondita, 2006, p. 62). Uma análise deste auto-retrato em rerlação com o cusano De non aliud foi oferecida por E. FILIPPI, Umanesimo. Dürer tra Cusano e Alberti, Verona, Arsenale, 2011, pp. 156-159.

${ }^{15}$ A. De SAnTis, Metamorfosi dello sguardo. Il vedere fra mistica, filosofia ed arte, Roma, Studia Anselmiana, 1996, p. 151

${ }^{16}$ N. Cusano, De visione Dei (1453), in Idem, Scritti filosofici, ed. con testo latino a fronte, a cura di G. Santinello, vol. II, Bologna, Zanichelli, 1980, par. VI, 
Ao alto, à direita do auto-retrato 'cristoforme' lê-se, além do mais: "Eu, Albrecht Dürer de Nuremberga, com a idade de 28 anos, com cores duráveis criei-me a mim próprio à minha imagem" (Albertus Durerus Noricus ipsum me propriis sic effingebam coloribus aetatis anno XXVIII) ${ }^{17}$.

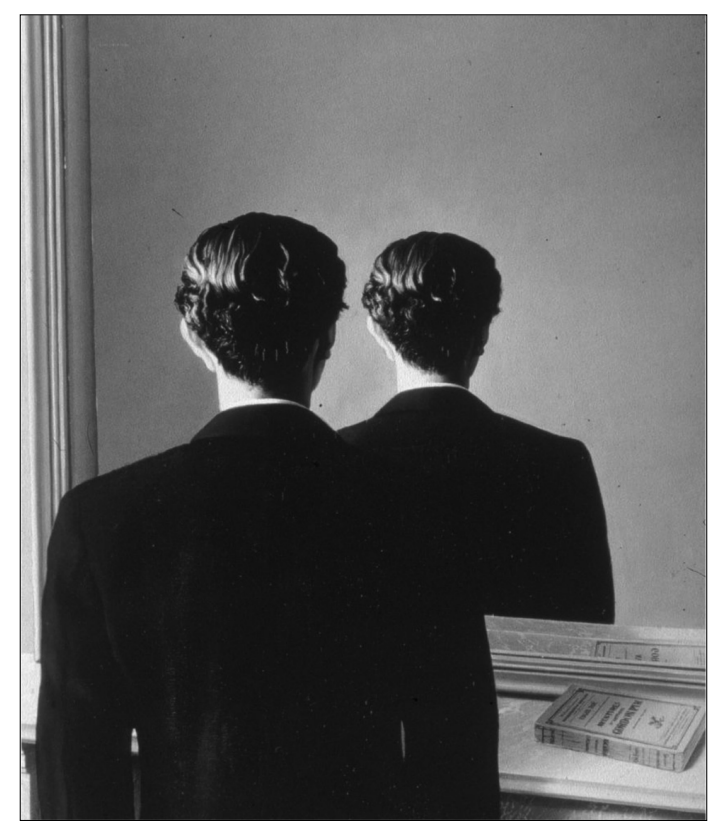

Foto. 3

Motivos teológicos, iconográficos e filosóficos parecem aqui fundidos magistralmente uns com os outros numa doutrina religiosa que tem o seu centro na imitatio Christi, o núcleo programático da Devotio moderna: Dürer representa-se a si próprio "à sua própria imagem" (nach meiner Gestalt, lê-se no auto-retrato que precede dois anos o que está em questão), mas com traços do rosto, olhar ubíquo, cabeleira típica dos ícones sagrados de Cristo, e até com a mão direita abençoa-

p. 279.

${ }^{17}$ Esta inscrição parece mais significativas do que aquela que acompanha o auto-retrato de 1498, exposta no Prado de Madrid: "Das malt ich nach meiner gestalt/Ich war sex und zwenzig Jor alt/ Albrecht Dürer". 
dora do Salvator mundi (ainda que secularizando a pose num gesto da mão aparentemente casual, mão dobrada sobre a pele do próprio manto que fica como que pinçado entre o indicador e o médio); de modo que "o efeito desta atitude hierática encontra apenas um paralelo nas figuras de Cristo de meio tronco" ${ }^{18}$. Dürer, dessa forma, cria-se a si próprio como reflexo num espelho, projectando a sua efígie no speculum infinitum do Verbo divino. Em tal auto-retrato, observou recentemente Hans Belting, Dürer representou o próprio rosto como se o tivesse capturado sobre o fundo infinito do espelho de Deus, sendo guiado na sua realização artística pela "procura de uma 'imagem originária" " ${ }^{19}$, Urbild guardada na faculdade teológica da memória. Ora, nesta sobreposição de traços, em que rosto humano e rosto divino parecem prescrutar-se reciprocamente como num jogo de espelhos, o homem conhece-se a si próprio como viva Dei imago, efígie viva do Homem-Deus, a "cópula da natureza divina criante e da natureza humana criada" ${ }^{20}$.

A segunda obra, bem mais recente, representa um caso radicalmente diferente do que acabámos de examinar. No quadro de Magritte, com efeito, parafraseando Benjamin leitor de Kafka, o homem que tenta recordar a própria origem encontra barrada a estrada 'da recuperação' do próprio osso occipital: a história do sujeito, que deveria reflectir-se na superfície especular das recordações bem estendida diante de si, continua - sempre e seja como for - a estar às costas do eu como alguma coisa de incircundável. Esta experiência, para citar uma carta de Magritte a P. Colinet (de 1957), é definida como o "encantamento da estranheza" do sujeito: aqui, uma coisa muito familiar, o moi, é obervada com um sentimento de estranheza" ${ }^{21}$, gerando nas recordações um efeito perturbador que ataca as certezas monolíticas do eu. A recordação, nesta imagem que se nega a si própria (um caso excepcional de iconoclastia que acede à imagem) está indisponível, a história não é reversível, o sujeito desdobrou-se irremediavelmente, e a laceração

${ }^{18}$ E. PANOFSKY, op. cit., p. 62.

${ }^{19}$ H. Belting, Das echte Bild. Bildfragen als Glaubensfragen, München, Beck, $2006^{2}$ (trad. it. La vera immagine di Cristo, a cura di A. Cinato, Torino, Bollati Boringhieri, 2007, p. 128).

${ }^{20}$ N. Cusano, op. cit., par. XX, p. 351.

${ }^{21}$ R. Magritte, Écrits complets, a cura di A. Blavier, Paris, Flammarion, 1979 (trad. it. Scritti, a cura di L. Sosio, Milano, Abscondita, 2005, vol. II, fram. 132, p. 89). 
entre o moi e o même jaz enrijecida aos pés da memória sem poder dar acesso a algum momento de verdadeiro reconhecimento - de tal modo que o eu e o mesmo, como num jogo de espelhos justapostos, reenviam infinitamente a própria imagem como o outro do outro, impedindo que o círculo do reconhecimento anamnésico possa fechar-se no 'Eu (o que recorda) $=\mathrm{Eu}$ (o que é recordado). A testemunhar a falta de um cais seguro da parte da viagem da memória nas regiões incógnitas do eu, aparece depois na tela - em baixo e à nossa direita - o Gordom Pym de Edgar Allan Poe, uma outra cifra narrativa do estranhamento do si. Ainda que ele se reflicta no espelho invertido - se dermos azo às aventuras de Mr Arthur Gordon Pym, escritas justamente um século antes da realização da tela - é um emblema da errância sem repatriamento do sujeito, uma subversão verdadeira e própria da teoria do Bildungsroman. A história de Poe, depois de motins, massacres cruentos e naufrágios de todo o tipo, acaba com a aparição, entre as vagas do oceano, de uma enigmática e imensa figura humana coberta por um manto branco, cuja pele "tinha a cor da neve" - espectro que assume as valências de um presságio certo da morte. A situação aqui representada é, pois, a do ponto de não retorno do eu, uma espécie de "afélio" do mesmo, onde o sujeito orbita no ponto da máxima distância do centro orbital da própria identidade. Se, pois, no fim da narração de Poe é descrito o xeque do romance de formação, na tela é representada - juntamente com a impossibilidade do próprio auto-retrato - a não-disponibilidade da verdadeira imago do eu contida pela memória, imagem que escapa a qualquer pensar reflexivo e a todo o recordar.

Mas vamos a Benjamin e Kafka. Benjamin, como é conhecido, dedicou páginas significativas ao grande narrador de Praga. Kafka, segundo Benjamin é o autor da indisponibilidade das recordações e das distorções aberrantes da memória, em que os Eingedanken e as Erinnerungen - colhidas no ponto da máxima distância do eu - se tornam cifras perturbantes de uma experiência vivida que está sob o signo de um castigo sem nome (como é descrito magistralmente no conto alucinado Na colónia penal, onde a culpa pela qual se foi condenado é inscrita nas costas dos condenados, de um tal modo que nenhum conheça a verdadeira entidade da infracção cometida). Os seus romances, além disso, são portentosas alegorias da falta humana de esperança, sendo as personagens que os animam condenadas a uma pena eterna que prescinde de qualquer gesto ou acção consciente: no mundo de Kafka é-se 
condenado e basta, sem possibilidade de apelo, só pelo facto de existir. "Os seus ajudantes - escreve Benjamin - são sacristães que ficam sem paróquia, os seus alunos, estudantes sem escrita" ${ }^{22}$, enquanto toda a sua obra é constituída por parábolas que não encontram solução (quase satíricas) perante o que sobressai enigmática a ideia da redenção como a impossibilidade mais própria deste ordenamento mundano: quase como uma "consolação que se dá para aqueles que já não têm esperança de consolação" ${ }^{23}$.Não resta senão fazer rolar incessantemente a pedra do acontecer histórico, "como Sísifo faz com a sua pedra", porque nada de novo - em particular o Novum histórico - pode sobrevir no theatrum mundi de Kafka ${ }^{24}$; como que a dizer la nouveauté c'est interdit.

No mundo de Kafka, assim escreve Benjamin em Destino e carácter, está-se como que imerso no "contexto culpável (Schldzusammenhang) daquilo que vive" ${ }^{25}$, onde "a lei [...] cessa de existir como tal e se confunde com a vida" ${ }^{26}$. Estar exposto a uma Lei "sem rosto e sem nome", que como tal culpabiliza a própria 'vida nua' do homem, significa ter esquecido a própria origem, ter perdido o sentido do próprio existir; além disso, como já se lê em Hobbes, Auctoritas, non veritas facit legem ${ }^{27}$ - e a autoridade, no mundo de Kafka, golpeia sempre como mero fado e destino. A memória, além disso, em vez de se estruturar, como em Agostinho, na forma de um grande templo ou de um mar calmo que acolhe o sujeito à procura de si, é aqui um labirinto no qual alguém se perde - como Kafka deixa pressagiar nas descrições dos poeirentos, escuros e labirínticos corredores do tribunal. Desates corredores, lê-se em $O$ processo, acedia-se, através de portas toscas aos vãos particulares do sótão pouco iluminados, divididos por simples caniços, dentro dos quais "se podiam ver funcionários a escrever

${ }^{22}$ W. Benjamin, Gesammelte Schriften II/2, p. 452 (trad. it. in Opere complete, a cura di E. Ganni, Torino, Einaudi, vol. VI (Scritti1934-1937), 2004, p. 152).

${ }^{23}$ IDEM, Gesammelte Schriften I/3, p. 124 (trad. it. Sul concetto della storia, a cura di G. Bonola e M. Ranchetti, Torino, Einaudi, 1997, p. 76).

${ }^{24}$ IDEM, Gesammelte Schriften II/2, p. 429 (trad. it. in Opere complete, cit., vol. II (Scritti 1923-27), 2001, p. 145).

${ }^{25}$ IDEM, Gesammelte Schriften II/1, p. 175 (trad. it. in Angelus Novus. Saggi e frammenti, a cura di R. Solmi, Torino, Einaudi, 1982 , p. 35).

${ }^{26} \mathrm{G}$. Agamben, Homo sacer. Il potere sovrano e la nuda vita, Torino, Einaudi, $2005^{2}$, p. 61 .

${ }^{27}$ T. Hobbes, Leviatahan (1651), cap. XXVI. 
à mesa": atarefadíssimos, mas com ar enfadado e distraído; enquanto uma rede fixa de escadas e escadinhas se elevavam um pouco por todo o lado, dando a impressão - quase como que suspensas sobre o nada de não levar a nenhum lugar preciso. Atravessar estes corredores que parecem intermináveis em que o protagonista vai à procura da própria inocência (entre as recordações claro-escuras das acções cometidas), dá um pouco a sensação de estar sobre um navio e não sobre terra firme: K., o protagonista, novo Gordon Pym assediado pelas ondas paludosas da justiça, "cria estar sobre um navio num mar tormentoso [...] como se o corredor ondulasse de um lado para o outro, e como se os acusados à espera em ambos os lados se elevassem e abaixassem" 28

Como não pensar aqui nas labirínticas prisões representadas por Giovan Battista Piranesi? De tal espécie, escrevia Aldous Huxley, "eram os castelos, os tribunais, as colónias penais habitadas pelas personagens dos romances de Kafka. Passando do mundo das palavras ao das formas, encontramos estas mesmas prisões metafísicas delineadas com força incomparável nas mais estranhas e em certos aspectos mais belas gravuras de Piranesi" ${ }^{29}$. Mais que reproduções de interiores existentes, em que se pode efectivamente 'habitar', estas águas-fortes descrevem um "mundo embrulhado sobre si próprio [...] matematicamente infinito" ${ }^{30}$, em que é fácil perder não só a orientação espacial, mas até a própria identidade. A meio caminho entre o porão de um antigo veleiro fantasma, antro satânico e sala de tortura da Inquisição, as tábuas de Piranesi - esta é a sugestão que proponho - são imagens arquétipas do removido que se prestam bem a descrever o mundo decaído de Kafka. Olhemos em simultâneo para a tábua XIV, na sua secunda variante da série (de cerca de 1761); nela, nota o historiador de arte Focillon, "a vista perde-se em tais complicações e qualquer ponto de apoio no terreno parece escapar-lhe. Ora o espectador está suspenso por cima de um abismo. Ora estamos sobre o patamar de uma escadaria colossal que num lado imerge nas trevas e no outro parece perder-se sobre a altura

${ }^{28}$ F.KAFKA,DerProzess (1925), in Gesammelte Werke, acuradiHans-GerdKoch, Frankfurta.M.Fischer,1994,vol.3(trad.it.Ilprocesso,Milano,Adelphi,1978,p.159).

${ }^{29}$ A. HuXley, On Piranesi's Prisons (1949): http://www.johncoulthart.com/ feuilleton/2006/08/25/aldous-huxley-on-piranesis-prisons/

${ }^{30}$ M. Yourcenar, Sous bénéfice d'inventaire, Paris, Gallimard, 1988 (trad. it. A beneficio d'inventario, a cura di F. Ascari, Milano, Bompiani, 2004, p. 86). 
das abóbadas" ${ }^{31}$. Parece-me este um lugar de errância por antonomásia; para uma confirmação posterior de um seu estranho parentesco com o mundo de Kafka, depois, muitos dos interiores representados escondem, envolvidas pela penumbra, monstruosas máquinas de que não se chega a compreender a função e terríficos instrumentos de tortura aumentando assim o sentido de cumplicidade entre espaço inabitável da prisão, labirinto da memória e o esvoaçar de uma grave culpa que não tem nome.

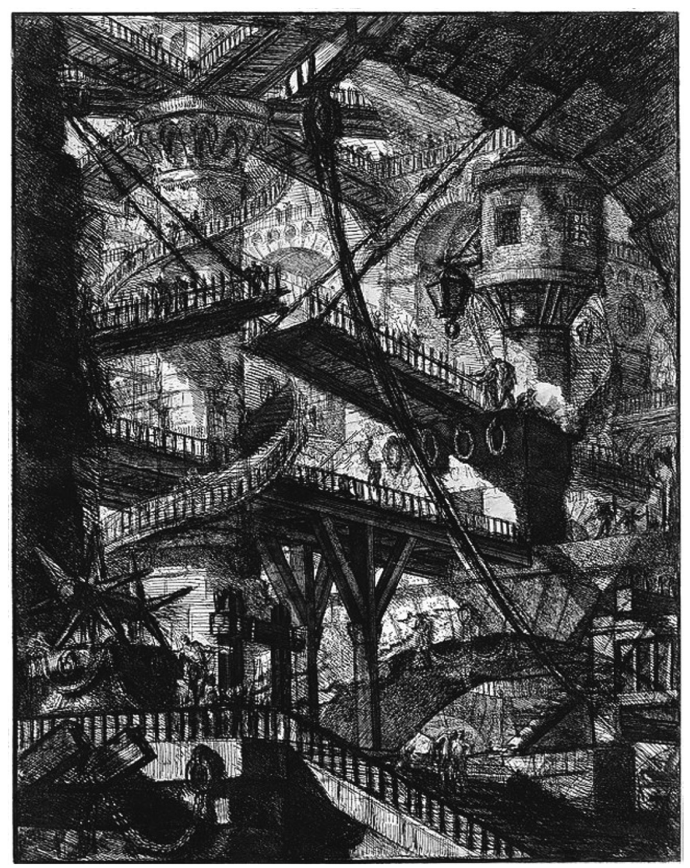

Foto 3

Proporei agora, de acordo com os dois paradigmas da memória antes mencionados, representar a variante kafkiana (em alternativa à

${ }^{31}$ H. Focillon, Prefazione a Giovanni-Battista Piranesi. Essais de catalogue raissoné de son æuvre, Paris, Henri Laurens, 1918 (trad. it. L'invenzione delle carceri, in Giovan Battista Piranesi, Le carceri, a cura di M. Praz, Milano, Abscondita, 2011, p. 137). 
imagem augustiniana do grande templo) com um dos 'pesadelos de cobre' gerados pelo engenho e executados pelo buril de Piranese - o que permite assim ligar o paradigma da errância, reflectido a nível subjectivo pelo enigma de Magritte, a uma das topografias de pesadelo presentes nas tábuas das Prisões piranesianas: a perda do sujeito (representada pela Reproduction interdite) coalha-se então espacialmente na constelação congelante da prisão, enquanto a nível narrativo ela vive nos sótãos cheios de pó e nos silêncios dos obtusos empregados descritos por Kafka, autor ao qual quero voltar em breve.

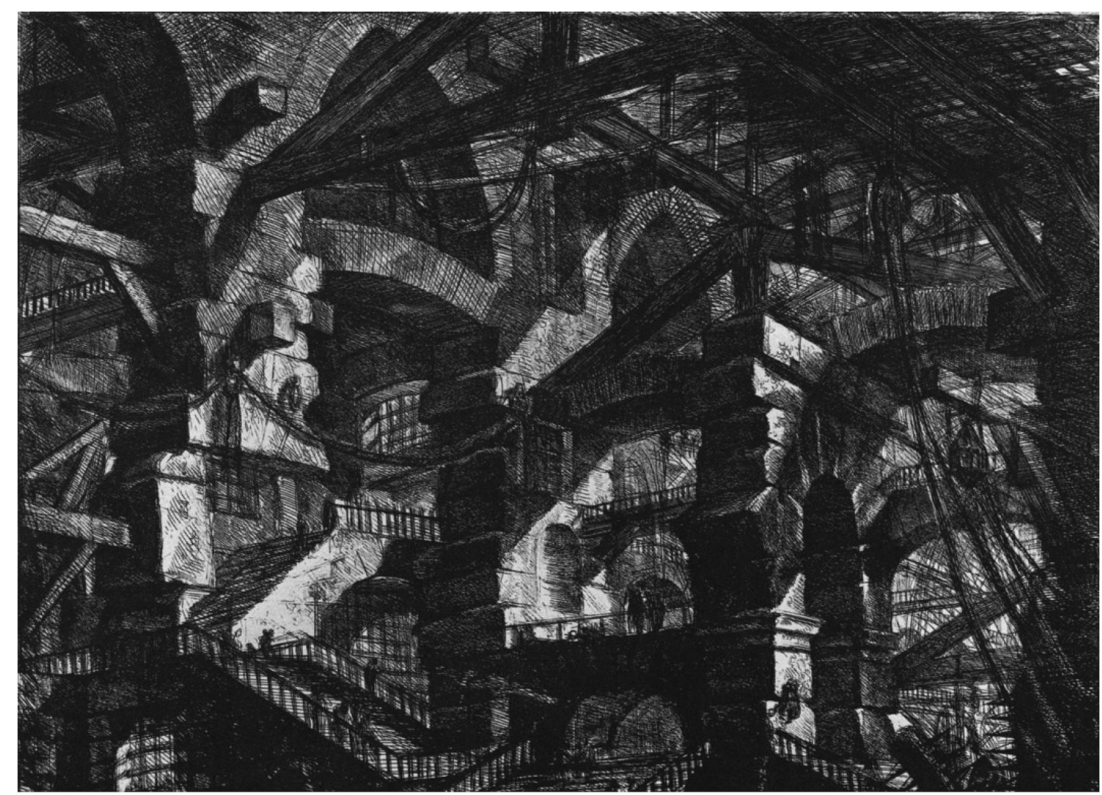

Foto 4

Recordar momentos da própria experiência vivida, no mundo mítico de Kafka, significa extrair achados fragmentários e incompreensíveis de uma história arcaica, em que antes de qualquer justiça a punição "cria por si própria o próprio culpável" ${ }^{32}$. Trazendo estes fragmentos

${ }^{32}$ W. Benjamin, Gesammelte Schriften II/3, p. 1234 (trad. it. Sul concetto di storia, cit., p. 94). 
míticos à luz do sol, todavia, produzem-se estranhos efeitos, anomalias espácio-temporais, alterações da lógica ordinária - como se o mundo inteiro fosse penetrado insensivelmente por leis físicas e morfológicas alternativas àquelas sobre as quais se rege o nexo causal dos fenómenos. Procurar a própria inocência nas profundidades do eu, em tal sentido, poderia conduzir - em vez de à recuperação da própria história passada - a uma pré-história terrificante (Vorgeshichte), em relação a cujo poder mudo e implacável não existe possibilidade de apelo. De facto, escreve ainda Benjamin, Kafka pôde ver, "no espelho que a pré-história lhe apresentava sob a forma da culpa, o futuro sob a forma do juízo" de condenação, como "se o procedimento [...] passasse lentamente para o veredicto" ${ }^{33}$.

Talvez, observa Benjamin, "a obrigação de se apresentar a julgamento suscite uma sensação semelhante à de abrir um baú fechado há anos no chão", em que o baú é o símbolo de uma culpa misteriosa e daquilo que foi esquecido: "Pediremos de boa vontade este cometimento até ao fim dos tempos [...]"34. Entretanto, na tentativa falível de recordar, deslizamos lentamente para um mundo marcescente e espectral, "cuja luxúria desenfreada é mal vista pelas puras potências da luz celeste" - e aqui basta recordar o episódio vivido pelo protagonista de $O$ Castelo com Frieda, a rapariga que serve a cerveja na sala da adega aos pés do castelo; o seu abraço acontece entre a sujidade e as poças de cerveja no chão, momento frenético que produz no protagonista - nem o dizendo - a sensação do esquecimento de si e um sentimento de profunda estranheza em relação às coisas que o circundam: por outro lado, o castelo é uma No mans land em que alguém se perde até ao ponto de não retorno.

Abraçaram-se, aquele pequeno corpo [de Frieda: $N d a$ ] ardia nas mãos de K.; num esquecimento de si de que K. procurava subtrair-se mas em vão, rolaam uns passos mais além, chocaram com um rumor surdo contra a porta de Klamm, depois viram-se estendidos entre poças de cerveja e outras porcarias de que o chão estava coberto. Passaram assim horas, horas

${ }^{33}$ IDEM, Gesammelte Schriften II/2, p. 427 (trad. it. in Opere complete, cit., vol VI, cit., p. 143).

${ }^{34}$ IDEM, Gesammelte Schriften II/2,p. 431 (trad. it. in Opere complete, cit., vol. VI, cit., p. 147). 
de respirações misturadas, de corações que batiam em conjunto, horas durante as quais $\mathrm{K}$. tinha a sensação constante de perder-se ou de se ter dirigido a uma terra estrangeira como nenhum homem antes dele, num país onde o próprio ar não tinha um só elemento em comum com o ar da terra natal, onde o sentimento de estranheza parava a respiração e todavia mais não se podia fazer, no meio daquelas seduções insensatas, do que seguir em frente e perder-se ainda mais ${ }^{35}$.

O esquecimento de que são afectados os protagonistas dos romances de Kafka, lembra Benjamin, está em contacto estreito com este "mundo inferior", impregnado de pura materialidade afectada por uma doença que gera um estado febril, embrutecimento da consciência e pulsões descontroladas e entrópicas.

Quem vive nos baús poeirentos é Edradrek, uma das personagens mais bizarras criadas por Kafka: "o mais estranho bastardo que a história terá gerado com a culpa em Kafka" ${ }^{36}$. Trata-se de um ser misterioso, em forma carrinho de linhas parecido com uma estrela, que vive fechado nos baús colocados em sótãos não diferentes dos gabinetes judiciários do processo, para comparecer de tempos a tempos como "figura enigmática do que foi removido" - eis a forma distorcida que assumem as recordações deformadas em Kafka. Mas que sentido tem então extrair das regiões do esquecimento um tal objecto? De facto, a preocupação angustiante do pai de família é que, embora ele não pareça fazer mal a ninguém, pode sobreviver-lhes, rolando abaixo pelas escadas diante dos pés dos seus filhos, e dos filhos dos seus filhos", arrastando em seguida todo aquele fio" matizado de formas e cores em que é fácil tropeçar ${ }^{37}$ - como se a culpa sem nome incarnada por Odradeck se pudesse transmitir entre as gerações como que por contágio sem nunca dizer o sentido, a motivação de uma tal condenação.

Mas vamos então a Benjamin, procurando compreender se a sua filosofia permite sair das prisões aberrantes do esquecimento em que

${ }^{35}$ F. KAFKA, Der Schloss, in Idem, Gesammelte Werke, cit., vol. IV (trad. it. Il castello, a cura di A. Chiusano, Roma, Newton Compton, 2010, p. 150).

${ }^{36}$ W. Benjamin, Gesammelte Schriften II/2, p. 431 (trad. it. in Opere complete, cit., vol. VI, cit., p. 146).

${ }^{37}$ F. KAFKA, Die Sorge des Hausvaters (1917), in Gesammelte Werke, cit., vol. V (trad. it. Gli affanni del padre di famiglia, in Idem, I racconti, a cura di G. Schiavoni, Milano, BUR, 1986, pp. 231-232). 
se movem as personagens de Kafka. É de facto opinião minha que a posição de Benjamin propõe uma interessante alternativa tanto ao paradigma teomórfico de Agostinho, como ao da Errância da memória descrito ao nível do sujeito estranhado do par Auster-Magritte (a indisponibilidade do eu), e a nível topográfico do de Kafka-Piranesi (o labirinto culpabilizante da memória). Para expor a minha tese num só mote, Benjamin procuraria recuperar estilhaços de redenção na plenitude da dissipação de uma matéria afectada por uma culpa atávica, conciliando - como mostra Hans Castorp na Montanha encantada - "monstros da noite" e "culto solar dos deuses". Abfall der Geschichte, assim se intitulam não por acaso numerosos fragmentos de Passagen-Werk, é a resposta completamente benjaminiana aos paradoxos da memória, um terceiro paradigma que definirei Arqueologia ou anamanese do residual - onde a palavra 'resto' ou 'resíduo' não deve subvalorizar a sua função teológico-redentiva.

"Nada daquilo que aconteceu deve ser alguma vez dado como perdido" ${ }^{38}$, escreve Benjamin nas teses de história. Numa arqueologia material da modernidade como a benjaminiana, o histórico configura-se como o "farrapeiro" (Lumpensammler) à caça do que foi eliminado e do lixo esquecido do existente, mas atento às possibilidades emancipatórias, sempre futuríveis, latentes nestes mesmos pedaços e aparas do passado: "A origem é a meta" recita o exergo da Tese XIV sobre o conceito de história - uma citação de Karl Kraus; o que, para Benjamin significa que o Outro da história não é a nuca que impede a reflexão do si (o passado removido, como na imagem negativa de Magritte), mas antes o seu futuro redentor, cujos vestígios estão disseminados nos resíduos do passado: uma tal origem, escreve Agamben, "não poderá jamais resolver-se completamente em 'factos' que se possam supor historicamente acontecidos, mas é alguma coisa que ainda não deixou de acontecer" ${ }^{39}$.

Esta propensão benjaminiana para o residual, além disso, conjuga-se também com uma arqueologia psíquica própria e verdadeira (ou arqueologia do inconsciente da história), "desde o momento em que

${ }^{38}$ W. Benjamin, Gesammelte Schriften I/2, p. 694 (trad. it. Sul concetto di storia, cit., p. 23).

${ }^{39}$ G. Agamben, Infanzia e storia. Distruzione dell'esperienza e origine della storia, nuova ed. accresciuta, Torino, Einaudi, 2001, p. 48. 
- assim escreve Didi-Huberman - o trabalho da memória se articula antes de mais com o ritmo dos sonhos, dos sintomas e das obsessões, com o ritmo das remoções e dos retornos do que é removido, das latências e das crises" ${ }^{40}$. O cânone benjaminiano da memória, por outras palavras, "é a recuperação (Verwerterung) dos elementos oníricos ao acordar" ${ }^{41}$ : nas fissuras de sentido e nos saltos semânticos incarnados pelo detalhe inútil, em tudo aquilo que foi descartado, removido, alterado e esquecido (relativamente a qualquer funcionalização homologante do conjunto das coisas) está a última salvação para o homem. Aqui, talvez, entre os escombros da história passada, é dado de facto encontrar o deus dos trapos, o ferro-velho por excelência, ele próprio tornado trapo e fancaria por amor de um homem que se deve libertar de uma história "aparentada ao mito". Como que a dizer: a eternidade dá-se apenas nas eliminações do tempo, na celebração do 'detalhe inútil', na veneração daquilo que é mais pobre porque privado de função. De resto, o coleccionismo, como é sabido, representa para Benjamin "uma forma de memória prática [...] a mais inadiável entre as manifestações profanas de compenetração com o passado (entre as manifestações profanas da 'vizinhança'). E qualquer acto mínimo da reflexão política faz pois de qualquer modo época no comércio do antiquariado. Construímos aqui um despertar que sacode o kitsch do século passado e o "chama para reunir" (zur 'Versammlung')" 42.

A memória, então, é para Benjamin como uma chapa de cobre sobre a qual passou - para além do buril fantástico e perturbante de Piranesi - o sopro ligeiro do anjo que corre em socorro do homem, anjo cujo olhar piedoso procura restabelecer um princípio de ordem no universo temerosamente assimétrico das ruínas das prisões que se abre à sua presença: o próprio Messias, escreve Benjamin jamais se juntará, não virá para transfigurar o mundo no sentido de uma grosseira apocatás-

${ }^{40}$ G. Didi-Huberman, Devant le temps. Histoire de l'art et anachronisme des images, Paris, Les Èditions de Minuit, 2000 (trad. it. Anacronismo delle immagini, a cura di S. Chiodi, Torino, Bollati Boringhieri, 2008, p. 100.

${ }^{41}$ W. Benjamin, Gesammelte Schriften V/1, p. 580 (trad. it. Parigi capitale del XIX secolo. I "passages" di Parigi, a cura di R. Tiedemann, Torino, Einaudi, 1986, p. 602).

${ }^{42}$ IDEM, Gesammelte Schriften V/II, pp. 1016-1017 (trad. it. Parigi capitale del XIX secolo. I "passages" di Parigi, cit., p. 1045). 
tase, mas antes - como na ponderação misteriosa de Calderon - apenas "para o ajustar um pouco" 43.

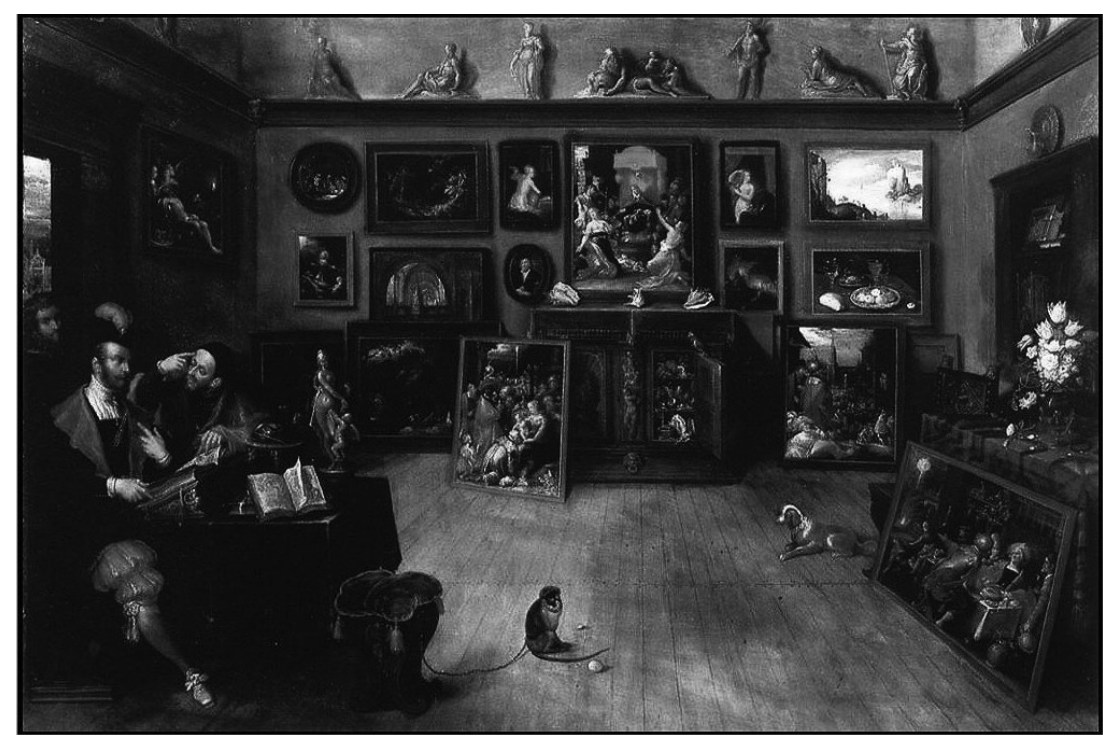

Foto 5

Nesse sentido, escreve ainda Benjamin pensando nos romances de Kafka, "a esperança é dada só a quem já não tem esperança" ${ }^{44}$, e é possível encontrar a via da identificação anamnésica até na plenitude da perda de si nos labirintos de pesadelo idealizados por Piranesi - com a condição de se activar a dialéctica histórica que Benjamin define como despertar, capaz de vislumbrar nas espiras adormecidas do passado "um índice temporal que o reenvia à redenção" (Tese II). Este despertar tem a forma de um som que espanta, que irrompe no sonho e se reacende

${ }^{43}$ IDEM, Gesammelte Schriften V/2, p. 432 (trad. it. in Angelus Novus. Saggi e frammenti, cit., p. 299).

${ }^{44}$ IDEM, Lettera a Scholem del 12 giugno 1938; in W. BENJAmin, Briefe, a cura di G. Scholem e T.W. Adorno, Francoforte, Suhrkamp, 1966, vol. II, p. 764 (trad. it. in Lettere 1913-1940, a cura di G. Scholem e T.W. Adorno, Torino, Einaudi, 1978, p. 348). 
com o que está mais próximo": o tornar-se consciente do saber acerca do que propriamente se foi tem pois para Benjamin a estrutura dialéctica do despertar de um pesadelo aberrante ${ }^{45}$. Para esse fim é necessário no entanto dissolver o aspecto granítico dos nossos sonhos aterrorizantes (aqueles "pesadelos de pedra" de que falava Balzac em Père Goriot, olhando os assim chamados mascarons, os grotescos que decoram a Pont Neuf); ou seja, estes pesadelos devem ser fluidificados na vida histórica aberta ao futuro, reencontrando "estilhaços messiânicos" verdadeiros e próprios entre os escombros que obstaculizam as masmorras em ruínas da história passada. A histoire interdite, então, não resiste ao olhar vigilante e consciente do historiador benjaminiano, olhar que o acompanha no empreendimento de "nadar contra a corrente" entre as vagas da história. Naquelas ruínas do tempo, desgastadas e despedaçadas, devemos saber descobrir uma insistente chamada para a nossa "débil força messiânica", a única capaz de recolocar no círculo da arena política o não cumprido que habita inerte nas profundidades adormecidas do passado.

Também no caso de Benjamin proponho evocar duas imagens, alegorias conceituosas da sua atitude em relação à memória - até porque éo próprio autor a exprimir-se, muito frequentemente, através de sugestivas "imagens de pensamento" (Denkbilder). A primeira é um emblema do sujeito histórico que recorda - e aqui refiro-me à célebre aguarela de Paul Klee, o Anjo da história, no centro das Teses sobre o conceito de história; a outra imagem não é senão a enésima representação topográfica dos lugares da memória, que - no caso de Benjamin, filho de um antiquário berlinense - desejaria assimilar à tela de Francken o Jovem A galeria do antiquário (1620): também na filosofia da história de Benjamin objectos de várias épocas e de estilos diferentes se olham atónitos, reclamando os olhares do visitante sobre a sua existência descontornada e desligada do fluxo temporal (semelhantes a 'mónadas', isoladas precisamente porque carregadas de sentido acabado). Trata-se de uma concepção policêntrica da história, desestruturada monadologicamente, "na qual qualquer época, estilo, modo de sensibilidade [...] aparece com o princípio de uma unidade de inteligibi-

${ }^{45}$ IDEM, Gesammelte Schriften V/2, p. 1213 (trad. it. Parigi capitale del XIX secolo. I "passages" di Parigi, cit., p. 61). 
lidade histórica autónoma, que tem o seu presente, o seu passado e o seu futuro específico" ${ }^{46}$.

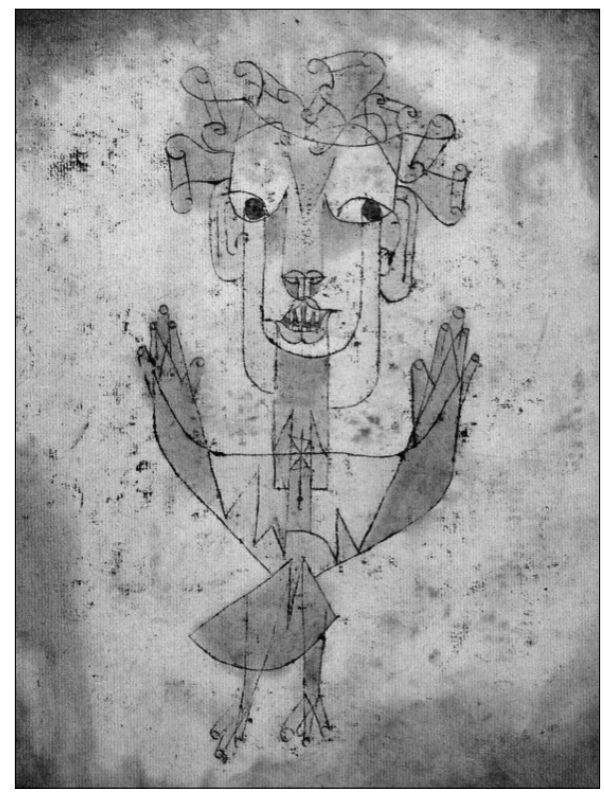

Foto 6

Vou então a Paul Klee, o ponto arquimediano da Tese IX. Antes de mais é necessário dizer que Benjamin, levando muito a sério as alegorias do nexo culpa-castigo que entretecem os romances de Kafka, estabelece como objectivo historicizar o mito da modernidade, levando a crítica histórica, através de uma dialéctica do despertar, a um contacto directo com o mundo palustre e demoníaco descrito pelo próprio Kafka - realidade marcescente que é a cifra exotérica do presente. O Anjo da história, entrevisto por Benjamin nos traços estilizados de Klee, quer recordar todas as desgraças do passado, porque tudo deve ser salvo. O Anjo, com o seu olhar cheio de pietas pela sorte humana, está em situação de ver às costas das "magníficas e progressivas sortes" uma

${ }^{46}$ S. Mosès, L'Ange de l'histoire. Rosenzweig, Benjamin, Scholem, Parigi, Seuil, 1992, p. 126. 
tempestade que acumula aos seus pés restos sobre restos, numa poderosa espiral de escombros que vai até ao céu: "O que nós chamamos progresso, escreve Benjamin, é esta tempestade". Só que, graças ao olhar compadecido do anjo, esta tempestade ruinosa é restituída ao plano da contingência: a longa série das desgraças é justamente história, uma sequência de acontecimentos completamente reversível, por isso ela não se identifica nem com "a rígida paisagem natural" do mito, nem com o destino. Numa palavra, é possível interromper o curso da história, puxar o "travão de emergência" da locomotiva progresso: esta, em última instância, "é a decisão de subtrair a humanidade, à última hora, à catástrofe que de vez em quando a ameaça" ${ }^{47}$.

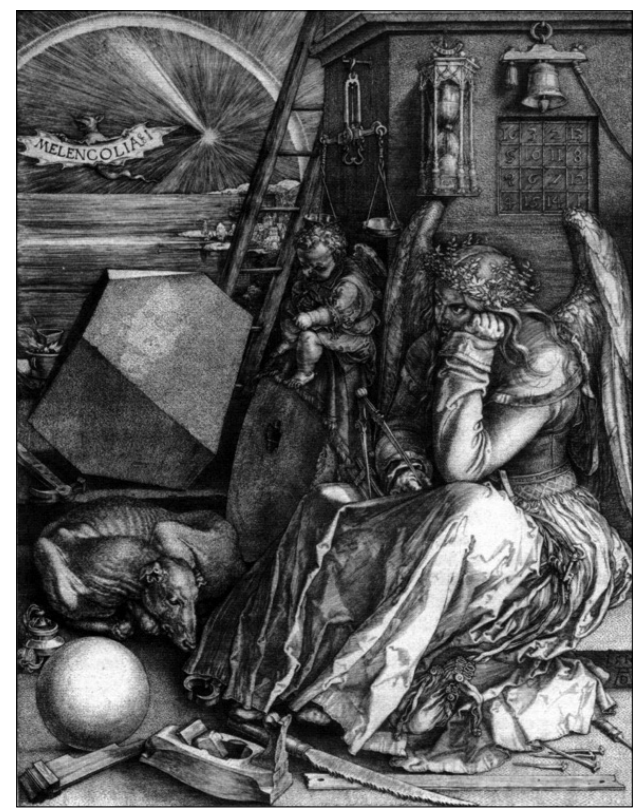

Foto 7

Não encontrei descrição mais bela do anjo benjaminiano do que a que é oferecida por Heiner Müller na poesia Der glückloser Engel (literalmente, $\mathrm{o}$ anjo desafortunado):

${ }^{47}$ W. Benjamin, Gesammelte Schriften I/3, p. 1232 (trad. it. Sul concetto di storia, cit., p. 101). 
Por detrás dele deposita-se o passado, espalha detritos sobre asas e costas, com um rumor quase de tambores sepultados, enquanto em frente dele estanha o futuro, penetra os seus olhos, e faz explodir as suas pupilas como estrelas, derrama a palavra em sonora mordaça, sufoca-o com a sua respiração. Por um instante, vê-se ainda o seu bater de asas, no balanço sentem-se cair as peças em frente sobre e atrás dele, sendo tanto mais rumoroso quanto mais impetuoso o vão movimento, esporádico, quando se torna mais lento. Depois sobre ele cumpre-se o momento: em pé, naquele lugar rapidamente cheio, o anjo melancólico serena, esperando a história na petrificação de voo olhar respiração. Até que o renovado rumor de um poderoso bater de asas se propaga em ondas através das pedras e anuncia o seu voo ${ }^{48}$.

Uma última referência benjaminiana, que vai ainda na direcção do repertório iconográfico: nas Teses sobre o conceito de história, descobre-se a presença irresistível, para além de uma explícita chamada de atenção para a aguarela de Klee, de uma remissão para a Melancolia I de Albrecht Dürer, célebre gravura de 1514 (recordo, a esse propósito, que Benjamin esteve em contacto epistolar com Aby Warburg, em cujo círculo de alunos e colaboradores - Panofsky, Saxle e Klibansky nasce o magnífico texto Saturno e a melancolia, em grande parte dedicado à representação düreriana) ${ }^{49}$. Faço aqui referência a uma constelação de conceitos que ressoam insistentemente nas teses de Benjamin, conceitos que parecem fazer referência a alguns elementos alegóricos que rodeiam a Dama alada da representação de Dürer: a clepsidra, a balança do acontecer histórico, o sino e as chaves do passado guardadas pelo saber vigilante e consciente do filósofo que indaga "o colo obscuro dos tempos". Procedo com ordem por pontos:

1. A clepsidra, colocada pouco acima da cabeça inclinada da Dama, na Tese XVII é o símbolo do correr do "tempo homogéneo e vazio do historicismo" - conceito inútil no plano político-revo-

48 H. Müller, Material, a cura di F. Hörnigk, Lipsia, 1989, p. 7 (trad. it. in M. Ponzi, Prefazione a L'angelo melanconico. Walter Benjamin e il Moderno, Roma, Lithos, 2001, p. 9).

${ }^{49}$ R. Klibansky, E. Panoksky, F. SAXL, Saturn and Melancholy. Studies in the History of national Philosophy, Religion and Art, Nelson, London, 1964. 
lucionário-redentivo projectado por Bernjamin. Esta concepção do tempo linear gera com efeito a acédia (a indolência, ou preguiça do coração), que cai no baile da meretriz "era uma vez" com que se entretém a concepção ordinária do tempo histórico;

2. A balança, que aparece na gravura sobre o atarefadíssimo menino, ainda na tese mal citada, é cifra da captura do tempo numa "constelação carregada de tensões". Ela, no seu equilíbrio precário, representa para Benjamin toda a consciência histórica autêntica. Em Passagen-Werk lê-se: no momento da decisão um prato está carregado do passado, o outro suporta a consciência do presente" ${ }^{50}$. Mais particularmente, a balança reenvia ao Stillstand, a "condição dialéctica da captura" (ou "captura messiânica do tempo": a instável e fugaz Gleichwichtigkeit temporal, na qual se aglutina a mónada 'instante-eternidade') capaz de tornar o tempo, no instante supremo do perigo, reversível, rompendo a conexão historicística entre os eventos segundo uma linearidade homogénea e vazia ${ }^{51}$ : "Quando o pensamento pára de súbito numa constelação carregada de tensões, proporciona-lhe um impacto pelo qual ele se cristaliza em mónadas. Nesta estrutura ele reconhece o sinal de uma captura messiânica do acontecer ou, dito por outras palavras, de uma chance revolucionária na luta pelo passado oprimido" 52 .

3. O sino, na gravura colocado sobre o quadrado astrológico de Marte (a mensula Jovis, objecto mágico da iatromatemática baseada no quatro, pelo seu carácter apotropaico capaz de funcionar como temperator Saturni), transforma-se na Tese XV em metáfora sonora: desaparece como elemento figurativo, mas res-

${ }^{50}$ W. Benjamin, Gesammelte Schriften V/1,p. 185 (trad. it. Parigi capitale del XIX secolo. I "passages" di Parigi, cit., p. 607).

${ }^{51}$ Esta Dialektik im Stilstand, escreve P. Missac, permite na concepção do tempo "a passagem da quantidade à qualidade" Esta suspensão é uma recusa aberta da concepção triádica hegeliana, que vê o acabamento só no terceiro elemento dialéctico (a síntese); ela, de facto, permanece suspensa numa coincidência dos opostos, carregada de tensões, capaz de fulgurar o decurso histórico à naeira de um "flash que, na noite, torna possível a imagem do instantâneo": Passage de Walter Benjamin, Parigi, Seuil, 1987, p. 123, 125-6.

${ }^{52}$ W. Benjamin, Gesammelte Schriften I/2, pp. $702-703$ (trad. it. Sul concetto di storia, cit., p. 51). 
soa como uma chamada à citation à l'ordre du Jour. Ele corresponde ao instante do despertar na constelação histórica do máximo perigo (exstremus necessitatis casus), assim como ao novo 'início estabelecido' do calendário revolucionário; este momento, capaz de suspender o fluir do tempo, é para o historiador "objecto de profecia" ${ }^{53}$. Pense-se, a esse propósito, na página dedicada por Benjamin à captura em Paris, no momento da revolução de Julho de 1830 , dos relógios com $\operatorname{sinos}^{54}$; um tiro de espingarda soa como o início de uma nova época, a da humanidade finalmente livre e realizada: o paraíso na terra. Os revolucionários parisienses, quais "novos Josués", para o tempo mecânico para fazer irromper no seu fluxo indiferenciado o qualitativo, carregado de estilhaços messiânicos -. Este despertar, como já foi recordado, tem a forma de um "som que espanta, que irrompe no sonho e se reacende com o que está mais próximo" 55 .

4. As chaves, penduradas à cintura do anjo melancólico, remetem para o "poder das chaves" possuído pelo saber histórico na actualidade do despertar, sobre que Benjamin escreve na Tese XVII/ bis $^{56}$. As chaves são capazes de fazer penetrar a consideração histórica (a crítica diurna, com o seu poder dissolvente em relação às trevas do que foi removido) no grande edifício da memória; em particular nas divisões secretas do passado, até então fechadas hermeticamente, imersas como estão no esquecimento e no torpor do sono - estado sonambular que é como que o efeito de uma culpa sem nome. Este estado onírico, na gravura, é representado pelo caniens dormiens, ou dormitans, muitas vezes colocado aos pés das representações canónicas da 'Dame Mérencolie', como um emblema do "aspecto obscuro do temperamento melancólico": dominado como é pelo baço (sobre o qual se difunde a doença da raiva, símbolo da perversão espiritual que se exprime

${ }^{53}$ IDEM, Gesammelte Schriften I/3, p. 1250 (trad. it. Sul concetto di storia, cit., p. 75).

${ }^{54}$ IDEM, Gesammelte Schriften I/2, p. 702 (trad. it. Sul concetto di storia, cit., p. 49).

${ }^{55}$ IDEm, Gesammelte Schriften V/2, p. 1213 (trad. it. Parigi capitale del XIX secolo. I "passages" di Parigi, cit., p. 61). p. 55).

${ }^{56}$ IDEM, Gesammelte Schriften I/3, p. 1259 (trad. it. Sul concetto di storia, cit., 
no enfurecimento do saber), muitas vezes apelava-se ao seu faro e à sua resistência para ver nele o emblema da procura infatigável e ruminante" ${ }^{57}$. A esta sonolência subtrai-se com o mesmo infatigável cuidado que caracteriza os alunos insones em Kafka, como se fosse uma espécie de alter secundário do temperamento melancólico. Estes, escreve Benjamin, dedicam-se a uma louca "cavalgada que se movimenta contra a tempestade que sopra do esquecimento": "[...] Uma atitude tão decidida, tão fanática, é a dos estudantes no estudo [...] Os escritores, os estudantes estão sem fôlego. Estão sempre em perseguição", à caça (Sie jagen nur so dahin), como se devessem em qualquer momento poder "responder no instante da sua chamada" 58 - Do sono louco do animal nascem mesmo os sonhos nefastos, como que "incubações geomânticas no tempo da criação" ${ }^{59}$, imersão lúgubre na vida secreta das coisas da criação surdas a qualquer revelação salvífica.

Em conclusão: da sobreposição da imagem de Klee e da de Dürer podemos adquirir dois importantes momentos de reflexão: o do acordar, emblema da crítica histórica, necessária para sair do labirinto do pesadelo gerado pelo esquecimento; e o da inquietação (Beunruhigung), sobre o qual Benjamin insiste na obra sobre As passages de Paris: este estado espiritual de tensão (hingespannt, diria Krakauer) "constitui o início de qualquer visão da história que possa legitimamente ser chamada dialéctica" ${ }^{60}$. Se nos resignamos à acédia, com efeito, o Anticristo jamais deixará de vencer a sua partida sobre o xadrez da história. Para citar um romance de Philip K. Dick, "acordai, vós que dormis!" De outro modo, antes ou depois, corremos o risco, como Gregor Samsa, de acordar na embaraçosa "massa do corpo" de um grande insecto, tão difícil de controlar: é efectivamente difícil imaginar uma prisão mais

${ }^{57}$ IDEM, Gesammelte Schriften I/1, p. 329 (trad. it. in Opere complete, cit., vol. II, cit., p. 189).

${ }^{58}$ IDEM, Gesammelte Schriften II/2, p. 435 (trad. it. in Opere complete, cit., vol. VI, cit., p. 150).

${ }^{59}$ IDEM, Gesammelte Schriften I/1, p. 330 (trad. it. in Opere complete, cit., vol. II, cit., p. 189).

${ }^{60}$ IDEM, Gesammelte Schriften II/2,p. 467 (trad. it. in Opere complete, cit., vol. VI, cit., p. 468). 
apertada do que esta, que só a custo deixa respirar, "seco e chato" como é este corpo monstruoso. Sobre as suas carnes mudas e quitinosas, como único vestígio do humano, quando muito poderia ser inscrita com uma grade a frase "honra o teu superior!", e sem pedir a razão do teu suplício - recordo apenas que em 1784 Kant, no panfleto Was ist Aufklärung, escrevia: "Tem a coragem de te servires da tua própria inteligência [...] Mas ouço gritar de todos os lados: não raciocines! O oficial diz: não raciocines, faz exercícios militares! O funcionário das finanças: não raciocines, paga! O eclesiástico: não raciocines, crê!" ${ }^{61}$.

Nem Piranesi teria sabido descrever melhor o esquecimento culpável do homem representado pelo corpo estranhado de Gregor Samsa. O sonho da razão produz monstros - para citar uma água forte de Goya de 1797. Esta advertência vale também para os nossos dias! ${ }^{62}$



Foto 8

${ }^{61}$ I. KANT, Werke, a cura di A. Buchenau ed E. Cassirer, vol. IV (Schriften von 1783-1788), Berlin, Bruno Cassirer, 1913, p. 171.

${ }^{62}$ Artigo traduzido por João Maria André. 